\title{
Film as a Tool for Teaching Arabic Cultures
}

\author{
Samar Zahrawi \\ Department of World Languages and Cultures \\ College of Humanities and Social Sciences \\ Sam Houston State University \\ Huntsville, Texas, USA
}

\begin{abstract}
This article is a narrative of the author's practice in teaching Arabic cultures to American college students. It suggests that using films as an educational tool will animate culture and promote intercultural competence. Films with their broad spectrum of themes and characters, present not only the general characteristics of a society, but also its subtleties and complexities. By humanizing the Arab world, the author hopes to raise awareness of stereotypes and promote understanding and empathy. A film alone, however, is inadequate as class material. This article describes the author's rationale in designing and teaching the class, and the way it has helped shift students' perspectives. First, the reasoning includes recognizing the stereotype together with its origin. Second, it establishes the cultural framework and themes. Third, it uses films to showcase contemporary issues and people's behaviors. The movies and documentaries, cited herein, are just examples, by no way inclusive, of how a film can be incorporated as class material to help put a human face to a diverse culture.
\end{abstract}

Keywords: Arabic culture, dispelling the stereotype, film as a teaching tool, intercultural competence, teaching Arabic cultures.

Cites as: Zahrawi, S. (2019). Film as a Tool for Teaching Arabic Cultures. Arab World English Journal for Translation \& Literary Studies3 (4)189-207.

DOI: http://dx.doi.org/10.24093/awejtls/vol3no4.16 